\title{
Does Hypovitaminosis A in Mothers Cause Congenital Malformation of the Eye?
}

\section{Shreya Shah, Mehul Shah*, Ashit Desai, Mrugesha Vaghela and Deeksha Thorat}

Drashti Netralaya, Dahod, Gujarat, India

*Corresponding Author: Mehul Shah, Drashti Netralaya, Dahod, Gujarat, India.
Received: August 11, 2020

Published: October 07, 2020

(C) All rights are reserved by Mehul Shah., et al.

\begin{abstract}
Introduction: Congenital malformation is an important cause of childhood blindness. Hence, we attempted to study the factors responsible for it.

Methods: This was a retrospective cohort study. We collected data from our hospital EMR for the period 2008 - 2019 . We retrieved the total number of paediatric outdoor and children with congenitally malformed eyes. We also explored the history of night blindness in mothers during pregnancy, exported the data to excel sheets, and calculated the type of anomalies using descriptive analyses with SPSS 22.

Results: Our cohort included 1435 children out of the total 100946 (1.42\%) outdoor of paediatric ophthalmology. We found various anomalies in our analyses. We discerned that 423 (29.47\%) cases had a history of night blindness to mother during pregnancy, suggesting vitamin A deficiency.

Conclusion: Based on our clinical observation, it could be concluded that hypovitaminosis A in mother results in maldevelopment and congenital anomalies of the eye in children.
\end{abstract}

Keywords: Vitamin A Deficiency; Congenital Malformation of Eye; Hypovitaminosis A in Mothers

\section{Introduction}

Blindness in children causes a deep impact on the psychological, emotional and socioeconomic growth of the family. It has been observed that unlike adult blindness, which is $80 \%$ avoidable (either preventable or treatable), only less than $50 \%$ of the causes are preventable in children. The prevalence globally has been reported to be as high as 1.5 per 1000 children in contrast to the high-income countries where the figure is only 0.3 per 1000 [1,2].

As the prevalence of blindness in children is relatively lower than that in adults, a large sample size is required to provide accurate data on the occurrence and causes of childhood blindness. The current rate is known to be $0.8 / 1000[3,4]$. The studies from India have shown that there has been an overall increase in congenital globe anomalies over the past two decades, and recent investigations have asserted that the condition contributes to nearly $40 \%$ of all causes of Childhood blindness [1-4]. To tackle the current causes of ocular morbidity attributed to whole globe and retinal abnormalities, a careful genetic counselling of parents before childbirth is necessary.

In India, 3,20,000 children ( $<16$ years) are blind, which constitutes $1 / 5^{\text {th }}$ of the world's blind children [4]. As reported by Dandona., et al. [3], the prevalence of blindness is $0.17 \%$ in Andhra Pradesh, which corresponds to 6,80,000 children (after extrapolation) (Vision 20202). 
The prevalence of childhood blindness was found to be $0.17 \%$ (95\% confidence interval 0.09 - 0.30). Treatable refractive error caused $33.3 \%$ of the blindness, followed by $16.6 \%$ resulting from preventable causes ( $8.3 \%$ each due to vitamin A deficiency and amblyopia after cataract surgery). The other major causes included congenital eye anomalies (16.7\%) and retinal degeneration $(16.7 \%)[3]$.

Upon examining the etiological causes, childhood disorders (mainly corneal infections) as a cause of blindness have declined in the Southern part of the country but are still prevalent in the North and Northeastern parts (especially in the rural pockets) [1,2]. Data also indicate that congenital anomalies and retinal causes are increasing in certain regions of the country [1,2].

However, the etiology is still not known for a majority of the causes (Khanna).

\section{Methods}

After obtaining approval from the Hospital Ethical Committee, we retrieved data from the Electronic Medical Records pertaining to the period 2008 - 2019. All children with congenital malformation were enlisted, and all information regarding the type of anomalies, family history, maternal history, and birth history of the child were acquired. Specifically, details regarding night blindness in mothers during the last trimester of pregnancy was collected. We documented the total number of fresh outdoor cases, number of children having congenital malformation of the eye, and mothers experiencing night blindness during the last trimester.

\section{Results}

Our cohort consisted of 1435 cases. We found that ---- children were totally examined at the Department of Paediatric Ophthalmology, of which 1435 (\%) children exhibited congenital malformation of the eye. Out of the 1423 (29.47\%) children having a history of night blindness in mothers, 1330 (92.7\%) were total globe anomalies and only 105 (7.3\%) constituted other anomalies. We encountered 250 (17.4\%) choroidal colobomas, 174 (12.1\%) iris colobomas, 248 (17.3\%) microcornea, 212 (14.8\%) microphthalmos, 236 (16.4\%) cryptophthalmos, 83(5.7\%) enophthalmos, and $306(21.3 \%)$ retinal degeneration and other anomalies such as hypertelorism, congenital optic atrophy, and persistent hyperplastic primary vitreous (PHPV) (Table 1).

\begin{tabular}{|l|c|c|}
\hline Type of Anomaly & Number & Percentage (\%) \\
\hline Iris coloboma & 174 & 12.1 \\
\hline Enophthalmos & 66 & 4.6 \\
\hline Microcornea & 248 & 17.3 \\
\hline Microopthalmos & 212 & 14.8 \\
\hline Retinal degenerations & 306 & 21.3 \\
\hline Cryptophthalmos & 17 & 1.2 \\
\hline Choroidal coloboma & 250 & 17.4 \\
\hline PHPV & 18 & 1.3 \\
\hline Congenital optic atrophy & 27 & 1.9 \\
\hline Other & 117 & 8.1 \\
\hline Total & 1435 & 100 type of anomalies \\
\hline
\end{tabular}

Table 1: Distribution of type of congenital anomalies.

\section{Discussion}

Congenital malformation of the eye is an important cause of childhood blindness. We had $29.47 \%$ mothers with a history of night blindness during pregnancy, which is suggestive of hypovitaminosis A. Many clinical studies have covered congenital malformation of the eye and its relationship with hypovitaminosis A. Many experimental studies have suggested that hypovitaminosis and folic acid deficiencies in mother leads to congenital malformations of the eye.

Mastereo-de-las., et al. have reported that mice exposed to a folic acid-deficient diet demonstrated numerous macroscopic eye anomalies, such as anophthalmia and microphthalmia. Microscopically too, the eye was the most affected organ $(43.7 \%$ of the fetuses) [5].

Yomai., et al. have documented that several putative genetic and environmental causes are associated with microphthalmia and anophthalmia, including vitamin A deficiency [6].

Bhattacharrji., et al. and Millemann., et al. have stated that the major anatomical causes of visual loss amongst 93 of the 258 patients (36.1\%) were congenital anomalies (anophthalmos and microphthalmos) [7].

Horneby asserted the presence of epidemiological and laboratory evidence supporting a hypothesis of genetic (recessive) predisposition to the teratogenic effects of mild-to-moderate maternal 
vitamin A deficiency during pregnancy. This fact may explain the high prevalence of congenital eye anomalies in certain Asian countries where maternal deficiency of the vitamin is common and consanguineous marriages are popular. Besides, other congenital malformations commonly found in association with ocular coloboma (e.g. Esophageal fistulae and heart defects in CHARGE association) might also be related to the deficiency [8].

The results revealed that $43 \%$ of the parents were consanguineous, $19 \%$ had a positive family history, and that the frequency of coloboma was the highest in the second-born children. Eleven $(16 \%)$ mothers had a history of night blindness while they were pregnant with the affected child, 7 ( $8 \%$ ) had consumed medication during the first trimester (abortifacients in two cases), 3\% had reported fever in the first trimester and 11 (13\%) had exposure to agricultural chemicals [8].

According to Ward., et al. during embryogenesis, information encoded in the genome is translated into cell proliferation, morphogenesis, and early stages of differentiation. Embryonic pattern arises from the spatial and temporal regulation and coordination of these events. The vitamin A (retinol) derivative, retinoic acid (RA), is essential for normal development. Mammalian embryos are protected against vitamin A deficiency by maternal retinoid homeostasis until the stored retinoids fall to very low levels. Retinol binding protein, which is synthesized in the yolk sac placenta of rodent embryos and in the syncytiotrophoblast of the human placenta, is imperative for the embryo to access retinol. Synthesis and metabolism of RA may involve cytoplasmic binding proteins, but the observation that mutants lacking these proteins are normal or near-normal suggests that they are not essential. Severe congenital vitamin A deficiency results in a spectrum of malformations, including defects of the eyes, lungs, cardiovascular system, and urogenital system [9].

Many other studies have also reported similar findings either in clinical or in animal studies [10-16].

\section{Conclusion}

Based on our clinical observation, it could be concluded that hypovitaminosis $\mathrm{A}$ in mother results in maldevelopment and congenital anomalies of the eye in children.

\section{Funding Support}

No financial support was received from any company or institution.

\section{Conflicting Interests}

None to declare.

\section{Bibliography}

1. Wadhwani M., et al. "Prevalence and causes of childhood blindness in India: A systematic review". Indian Journal of Ophthalmology 68 (2020): 311-315.

2. Khanna RC. "Commentary: Childhood blindness in India:Regional variations". Indian Journal of Ophthalmology 66 (2018): 1461-1462.

3. R Dandona and L Dandona. "Childhood blindness in India: a population based perspective". British Journal of Ophthalmology 87 (2003): 263-265.

4. G V S Murthy., et al. "Current status of cataract blindness and Vision 2020: The right to sightinitiative in India". Indian Journal of Ophthalmology 56 (2008): 489-494.

5. Maestro-de-las-Casas C., et al. "Maternal folic acid-deficient diet causes congenital malformations in the mouse eye". Birth Defects Research Part A: Clinical and Molecular Teratology 97.9 (2013): 587-596.

6. Yomai AA and BI Pavlin. "Microphthalmia and anophthalmia in Chuuk State, Federated States of Micronesia". Pacific Health Dialogue 16.1 (2010): 141-144.

7. Bhattacharjee H., et al. "Causes of childhood blindness in the northeastern states of India". Indian Journal of Ophthalmology 56.6 (2008): 495-4499.

8. Millemann Y., et al. "Ocular and cardiac Bhattacharjee malformations associated with maternal hypovitaminosis A in cattle". Veterinary Record 160.13 (2007): 441-443.

9. Hornby SJ., et al. "Eye birth defects in humans may be caused by a recessively-inherited genetic predisposition to the effects of maternal vitamin A deficiency during pregnancy". Medical Science Monitor 9.11 (2003): HY23-HY26.

10. Hornby SJ., et al. "Environmental risk factors in congenital malformations of the eye". Annals of Tropical Paediatrics 22.1 (2002): 67-77.

11. Morriss-Kay GM and N Sokolova. "Embryonic development and pattern formation". The FASEB Journal 10.9 (1996): 961968.

12. Palludan B. "The influence of vitamin A deficiency on foetal development in pigs with special reference to eye organogenesis". International Journal for Vitamin and Nutrition Research 146.2 (1976): 223-225.

13. Giroud A., et al. "[Congenital ocular abnormalities in vitamin A deficiency]". Ann Ocul (Paris) 195 (1962): 566-567. 
14. Roux C., et al. "[Congenital ocular anomalies in vitamin A deficiency]". Bulletin des Societes d'Ophtalmologie de France 62 (1962): 12-21.

15. Giroud A., et al. "Fetal eye malformations of the folic acid deficient rat]". Archives D'anatomie Microscopique Et De Morphologie Experimentale 43.1 (1954): 21-41.

16. Warkany J and E Schraffenberger. "Congenital malformations induced in rats by maternal vitamin A deficiency; defects of the eye". Archives of Ophthalmology 35 (1946): 150-169.

\section{Assets from publication with us}

- Prompt Acknowledgement after receiving the article

- Thorough Double blinded peer review

- Rapid Publication

- Issue of Publication Certificate

- High visibility of your Published work

Website: www.actascientific.com/

Submit Article: www.actascientific.com/submission.php

Email us: editor@actascientific.com

Contact us: +919182824667 